\title{
Single dose and pulsatile treatment with human growth hormone in growth hormone deficiency
}

\author{
P J SMITH, P J PRINGLE, AND C G D BROOK \\ Endocrine Unit, Middlesex Hospital, London
}

SUMMARY The growth and growth hormone profiles in four children receiving three different regimens of treatment with human growth hormone (hGH) were compared. There was no significant difference in the rate of growth between the regimens; the rate of growth fell dramatically after treatment. Pulsatile administration of hGH was no better than conventional treatment.

In the United Kingdom the conventional treatment of growth hormone deficiency has been 4 IU pituitary human growth hormone (hGH) given intramuscularly three times a week. ${ }^{1}$ In an attempt to reproduce the normal physiological pattern of secretion of growth hormone, and thus achieve a greater growth response, the same total weekly dose has been given in daily subcutaneous injections. ${ }^{2-4}$ Studies in animals, in which the hormone was given intravenously, indicated that frequent doses are more effective than occasional ones. ${ }^{5}$ There are no data about pulsatile administration of hGH subcutaneously either in animals or in man; we therefore studied the effect of pulsatile administration on the rate of growth in a small group of children deficient in growth hormone.

\section{Patients and methods}

Four prepubertal children deficient in growth hormone (one boy and three girls with a mean age of
$7 \cdot 6$ years, range $6 \cdot 1-11.4$ years) were studied. Three had already received the standard regimen ( 4 IU intramuscularly) and one was a new patient. The Table summarises their clinical details. The study was approved by the Middlesex Hospital ethics committee, and informed consent was obtained from the patients' parents. Recruitment to the study stopped in May 1985, when hGH was withdrawn from the market.

A single blind study was performed. Each child received, in random order, one bolus of $2 \mathrm{IU} h \mathrm{hH}$ or three boluses of $0.6 \mathrm{IU}$ hGH each night for six nights through a 27 gauge infusion needle inserted subcutaneously into the anterior abdominal wall, a mini infusion pump (engineering department of the National Institute for Medical Research, Mill Hill) was used. An interval of 3.3 hours separated each dose in the multiple pulse regimen. The hGH was prepared weekly and kept in a refrigerator. After six months each child changed to the other regimen.

Growth hormone profiles were constructed for each child during the three regimens, blood samples being taken at 20 minute intervals, for 12-24 hours, through an indwelling heparinised venous cannula. Serum growth hormone concentrations were measured by immunoradiometric assay.

Auxological data were collected at three monthly intervals by standard techniques. ${ }^{6}$ The rate of growth is reported as raw data (centimetres per year) and the standard deviation score, defined as $(\mathrm{X}-\overline{\mathrm{X}}) /$ $\mathrm{S}$, where $\mathrm{X}$ is the rate of growth, $\overline{\mathrm{X}}$ the mean rate of growth, and $\mathrm{S}$ the standard deviation for age and sex.

Table Clinical and auxological data

\begin{tabular}{|c|c|c|c|c|}
\hline & Case 1 & Case 2 & Case 3 & Case 4 \\
\hline Age at start of study (years) & $6 \cdot 1$ & $6 \cdot 6$ & $6 \cdot 4$ & $11 \cdot 4$ \\
\hline Diagnosis & GHD. TSHD & (iHD & GHD & GHI) \\
\hline Years of treatment with h(ill & $3 \cdot 5$ & $4 \cdot 0$ & $3 \cdot 5$ & Nonc \\
\hline \multicolumn{5}{|l|}{ Rate of growth: } \\
\hline Before treatment & $6.4(-1 \cdot 8)$ & $5.9(-1.8)$ & $4 \cdot()(-2 \cdot 9)$ & $4 \cdot 1(-2 \cdot(0)$ \\
\hline \multicolumn{5}{|l|}{ During treatment: } \\
\hline + IU h(ill intramuscularlỳ & $5.6(-0.7)$ & $6 \cdot 2(+0.9)$ & $3.9(-2 \cdot 3)$ & Not applicable \\
\hline 2 IU hoill subcutancously & $5 \cdot 6(-0.6)$ & $6 \cdot 1(+0.5)$ & $6 \cdot()(+0 \cdot 3)$ & $9 \cdot 9(+3 \cdot 8)$ \\
\hline $0.6 \times 3 \mathrm{~h}(\mathrm{iH}$ subcutancously & $5.4(+() \cdot 3)$ & $3.2(-2.9)$ & $6 \cdot 2(+0 \cdot 2)$ & $9 \cdot()(+3 \cdot())$ \\
\hline After treatment & $0.6(-5.7)$ & $3 \cdot 8(-2 \cdot(1)$ & $1 \cdot 4(-5 \cdot 1)$ & $3 \cdot 3(-2 \cdot 5)$ \\
\hline
\end{tabular}

(iHD = Growth hormone deficiency. TSHD $=$ Thyrotrophin stimulating hormone deficiency

Expressed as $\mathrm{cm} / \mathrm{year}$ with standard deviation score in parentheses.

SSteady state growth ratc. 


\section{Results}

The Table summarises the results. When given the conventional regimen the new patient showed "catch up' growth, which was maintained during both subcutaneous regimens. The rate of growth in the three children who had previously been treated was maintained or improved, although during the $0.6 \mathrm{IU}$ regimen in case 2 the rate of growth fell because of non-compliance.

The rate of growth and standard deviation score of each child fell dramatically after treatment stopped, the score falling from the mean pretreatment value of -2.1 (confidence interval -1.8 to $-2.9)$ to $-3.8(-2.5$ to 5.7$)$ after treatment.

The growth hormone profiles from one patient are shown in the Figure and compared with the profile of a 6 year old boy growing at a rate yielding a standard deviation score of $-0 \cdot 6$. Actual time is not shown as the injection times were not synchronous, spanning 2000-2100. The peak concentrations of growth hormone and areas under the curves were greatest during the highest dose regimen, but the mean time to the peak concentration was similar after $4 \mathrm{IU}$ hGH given intramuscularly, 2 IU hGH given subcutaneously, and the first pulse of $0.6 \mathrm{IU}$

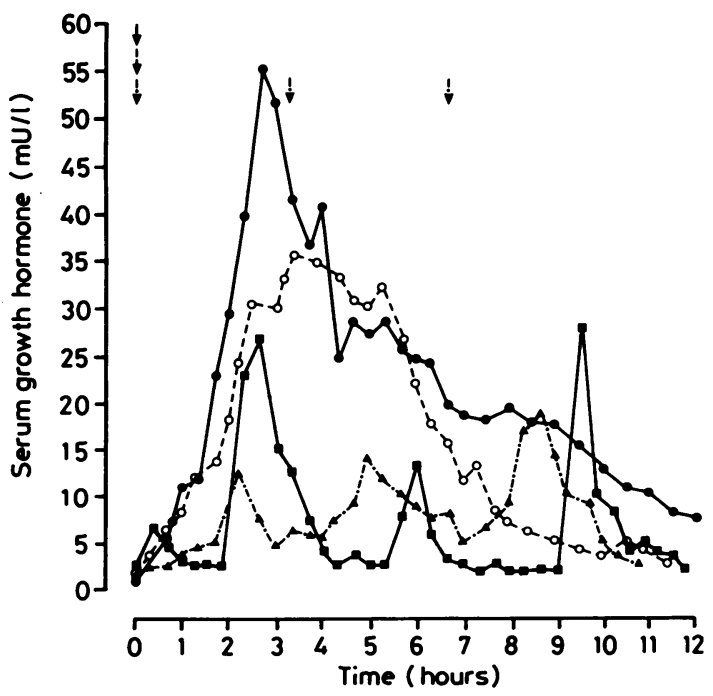

Figure Serum growth hormone profiles in a normal prepubertal boy $\longrightarrow$, and after $\downarrow 4$ IU human growth hormone administered intramuscularly after 2 IU human growth hormone administered subcutaneously $\bigcirc-\bigcirc$; and after 0.61 IU human

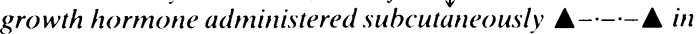
children deficient in growth hormone. given subcutaneously $(3 \cdot 6,3 \cdot 9$, and $2 \cdot 8$ hours, respectively); similar times were seen after the subsequent pulses. Peaks of growth hormone concentration were seen during the three dose regimen in all cases. The peak concentration and area under the curve were less than in the two other regimens, but the profile resembles the normal secretory pattern of growth hormone more closely than the profiles seen during the other regimens.

\section{Discussion}

In the United Kingdom a Medical Research Council working party concluded that an acceptable costbenefit ratio in the treatment of children deficient in growth hormone was achieved when a total weekly dose of $12 \mathrm{IU}$ hGH was given intramuscularly in three equal doses. ${ }^{1}$ Albertsson-Wikland et al and Kastrup et al reported improved growth when hGH was given daily but in the same weekly dose to children previously established on the conventional regimen. ${ }^{2} 3$ More frequent injections in animals have produced a greater growth response. ${ }^{5}$ In this small study we compared the effects on growth and serum growth hormone concentrations during treatment with $4 \mathrm{IU}$ hGH intramuscularly three nights a week, 2 IU hGH subcutaneously six nights a week, and 0.6 IU hGH subcutaneously six nights a week. We showed similar growth responses in all treatment groups despite greater serum concentrations of growth hormone during the two high dose regimens compared with the multiple pulse regimen. A longer study with larger numbers of patients to confirm or refute our results was not possible because hGH was withdrawn from the market.

We were unable to show any resemblance between the growth hormone profile after 2 IU hGH and the normal secretory profile, as reported by Christiansen $\mathrm{et} \mathrm{al},{ }^{+}$The multiple pulse regimen came closer to replicating the normal profile in childhood. To mimic normality higher doses of growth hormone are required, and it would probably have to be given intravenously as in the animal experiments. ${ }^{5}$

The growth rates fell noticeably after treatment. A similar phenomenon was observed in a matched group (age, sex, and pubertal development) of 15 children deficient in growth hormone whose pretreatment rate of growth standard deviation score of $-2 \cdot 1(\mathrm{SD} \mathrm{1.0)}$ ) fell to -3.2 (SD 1.5) during the period after growth hormone was withdrawn from the market $(\mathrm{p}<0) \cdot(01)$ (C G D Brook et al. Paper presented at meeting of European Society of Paediatric Endocrinology, Zurich, 1986). Tanner et al described 'regulatory' deceleration after withdrawal of treatment with hGH, with the effect waning by six months. ${ }^{7}$ We confirmed these findings 
but found that the phenomenon was still present nine to 12 months after the end of treatment.

The optimal treatment regimen has yet to be established, but this may now be possible as synthetic growth hormone becomes more widely available.

We thank the locally organised clinical research committee of the North East Thames Regional Health Authority and Children Nationwide Medical Research Fund for financial support.

\section{References}

${ }^{1}$ Milner RDG, Russell-Fraser T, Brook CGD, et al. Experience with human growth hormone in Great Britain: the report of the MRC working party. Clin Endocrinol 1979;11:15-38.

2 Albertsson-Wikland K. Westphal O, Westgren U. Daily subcutancous administration of human growth hormone in growth hormone deficient children. Acta Paediatr Scand 1986;75:89-97.

${ }^{3}$ Kastrup KW, Sandahl-Christiansen J, Anderson JK. Orskov H. Increased growth rate following transfer to daily s.c. administra- tion from three weekly i.m. injections of hGH in growth hormone deficient children. Acta Endocrinol 1983:104:148-52.

+ Sandahl-Christiansen J, Orskov H. Brinder C. Kastrup KW. Imitation of normal plasma growth hormone profile by subcutancous administration of human growth hormone in growth hormone deficient children. Acta Endocrinol 1983:102:6-10.

5 Clark RG, Jansson JO. Isakson O. Robinson ICAF. Intravenous growth hormone: growth responses to patterned infusions in hypophysectomised rats. J Endocrinol 1985:104: 53-7.

' Brook CGD. Growth assessment in childhood and adolescence. Oxford: Blackwell Scientific Publications, 1982.

7 Tanner JM, Whitehouse RH, Hughes CR. Vince FP. Effect of human growth hormone treatment for 1 to 7 years on growth of 100 children with growth hormone deficiency, low birth weight. inherited smallness, Turner's syndrome and other complaints. Arch Dis Child 1971:46:745-782.

Correspondence to Dr C G D Brook. Middlesex Hospital, London WIN 8AA.

Received 15 December 1986

\title{
Diagnosis of rotavirus gastroenteritis by smell
}

\section{J POULTON AND M J TARLOW}

\author{
East Birmingham Hospital, Birmingham
}

\begin{abstract}
SUMmary Clinical features cannot differentiate rotavirus gastroenteritis from other types of diarrhoea. Sixty eight stool specimens were examined by nurses on an infant gastroenteritis ward. Of these, $69 \%$ were correctly classified by smell alone. The results are significant $(p=0.009)$ and support the suggestion that rotavirus stools have a characteristic smell.
\end{abstract}

The appearance and smell of stools have always interested physicians, ${ }^{1}$ and the smell of the stool has provided an important clue in establishing the original link between enteropathogenic Escherichia coli and neonatal gastroenteritis. ${ }^{2}$ The present study was undertaken because it was noticed that the nurses on a paediatric infectious disease ward usually diagnosed rotavirus gastroenteritis correctly before the results of culture were available. They considered the appearance and smell of the stools to be of diagnostic value. Our aim was to test the hypotheses that rotavirus gastroenteritis could be diagnosed by either the smell of the stool alone, or a combination of smell and appearance.

\section{Patients and methods}

Overnight stools were collected from 23 babies with diarrhoea, aged 0-18 months (mean 4.8 months), and coded by night staff. Table 1 shows the causes of the diarrhoea. The stools were randomised and examined by day staff at 9.00 am the next morning.

Each stool was examined in two ways. The first way by smell alone, the specimen pot being wrapped in a paper towel, and the nurse keeping her eyes closed. She was asked to classify it as rotavirus or not rotavirus; 'don't know' was not allowed. For the second examination the paper towel was removed and she was asked to inspect the stool and given the opportunity to change her opinion. Seven nurses made 68 examinations of 33 stool specimens over three months.

The ages of the children, the feeds given, and the ages of the stools were comparable.

\section{Table 1 Diagnoses in 23 babies studied}

\begin{tabular}{lc}
\hline Diagnosis & No of babies \\
\hline Positive for rotavirus & 10 \\
Rotavirus only & 8 \\
Rotavirus and adenovirus & 1 \\
Rotavirus and enteropathogenic $E$ coli & 1 \\
Not positive for rotavirus & 13 \\
Adenovirus & 2 \\
Campvlobacter & 1 \\
Respiratory infections & 4 \\
Cystic fibrosis & 2 \\
No organism isolated & 4 \\
\hline
\end{tabular}

